\title{
Ultrasonographic and Other Testicular Characteristics of Holstein Bulls Revisited
}

\author{
Joachim HAHN, James R. STOUFFER and Robert H. FOOTE
}

Department of Animal Science, Cornell University, Ithaca, New York 14853, USA

\begin{abstract}
The testes of bulls in an artificial breeding unit were examined with low frequency (1.6 and $2.25 \mathrm{MHz}$ ) transducers to determine if acoustical impedance could be used to detect bull differences in testicular tissue. The initial studies accompanied measurement of the linear dimensions and circumference of the testes with simple calipers and tapes to estimate size. Simple instruments proved to provide testicular size information that was more accurate and more easily obtained than by ultrasonography. Subsequent studies dealt with spermatogenic elements. Internal characteristics of the testes of 10 normal young bulls measured by ultrasonography were similar and were not significantly correlated with semen characteristics. Ultrasonograms on the testes of 68 bulls 20 to 144 months old differed, particularly associated with age. There was more dense tissue distributed in the testicular parenchyma of older bulls. Twenty-six bulls that had preslaughter ultrasonic analysis of the testes were classified into two groups after slaughter on the basis of normal or high proportions of fibrous testicular tissue. An independent analysis of the ultrasonograms concurred $81 \%$ of the time with the postmortem findings. While ultrasonography has greatly aided the understanding of many events in reproductive development and sexual function, it appears that its capabilities of providing unique information on internal testicular characteristics may be limited to special cases, such as old bulls when semen quality is marginal.

Key words: Ultrasonography, Bull testes, Semen quality, Fertility.
\end{abstract}

(J. Reprod. Dev. 45: 405-410, 1999)

I

$\mathrm{n}$ recent years there has been an explosion in the application of ultrasonography. Reviews of its application to study reproductive biology of domestic animals by Griffin and Ginther [1] and Ribadu and Nakao [2] indicate that about $95 \%$ of these studies have dealt with female reproductive physiology. Given the complexity of reproduction and the internal anatomical arrangement of the female reproductive system, it is not surprising that a majority of the studies are on the female. However, there are many studies on male reproduction where ultrasound might have been included as a useful component, but was not used.

The male is of major importance in any breeding

Accepted for publication: October 8, 1999

Correspondence: R. H. Foote program. For example, the conception rate of up to tens of thousands of females in dairy cattle artificial insemination (AI) can depend, in part, upon the quality and quantity of sperm produced by an AI sire. Early studies by Willett and Ohms [3] demonstrated that there was a high correlation between testis size and sperm output of young bulls $(\mathrm{r}=0.92)$, whereas in a small sample of six aged bulls $r=-0.53$.

Our laboratory has been extensively involved in evaluation of testes, semen quality and fertility of dairy bulls for many years $[4,5]$. Our experiments demonstrated that it was possible to estimate testis size from various linear measurements in situ on animals ranging in size from rabbits [6] to boars and bulls [4, 7].

Many older bulls culled from an AI organization 
because of poor semen quality or fertility were slaughtered and reported by McEntee [8] to have fibrous tissue scattered throughout the testes. Testicular biopsies to evaluate problem bulls while alive caused too much testicular damage to be useful [8]. Subsequently a tonometer was developed to measure firmness of the testes [9] as a possible indicator of fibrosis or degeneration. Then ultrasound was being developed for biological application, and this technology theoretically offered a noninvasive method of identifying tissue of different densities that would alter the echo frequencies. First we undertook studies of the effects of ultrasonic radiation upon the rapidly dividing testicular cells, using the rabbit model [10]. Based upon the innocuous effects on rabbit testes, studies proceeded on utilizing ultrasonography to examine the testes of valuable breeding bulls.

The objectives of these early studies were to establish methodology to examine the whole testis and to detect internal testicular differences among bulls with high sperm output and semen quality versus those with poor semen quality. The results, using low frequency transducers are reported here.

\section{Materials and Methods}

Bulls were provided by Genex, Cooperative, Inc. Semen quality and testicular characteristics from external measurements were evaluated by methods described previously [7, 9].

Three experiments were conducted. In Experiments I and II a Branson Sonoray Velocimeter was used with the transmitters being $6.3 \mathrm{~mm}$ diameter transducers operating at a frequency of 1.6 or $2.25 \mathrm{MHz}$, and with an acoustical power of $1 \mathrm{~mW} / \mathrm{cm}^{2}$. A $2.25 \mathrm{MHz}$ transducer served as the receiver. The transducers were mounted on a sliding caliper so that the distance between the transducers could be easily adjusted to position a testis between them and make good contact without compression. This distance was measured. Paraffin oil was supplied to the face of the transducer to maintain proper contact and eliminate air between the surface of the transducer and the testis. The assembly was connected to an electronic counter to measure the frequency change in $\mathrm{mc} / \mathrm{sec}$. In Experiment I, testes of 10 bulls 34 to 42 mo of age were measured.
In Experiment II, testes of 68 bulls in two groups, 20 to 144 mo of age, were measured.

In Experiment III an ultrasonic animal scanner developed by Stouffer [11, 12], using a Branson Sonoray Model 12 unit with a $2.25 \mathrm{MHz}$ transducer was tested. The B-scan technique involved movement of a transducer on a fixed guide attached to a polyethylene container in which the testes were immersed in body temperature water at the time of scanning. A Polaroid camera back mounted on a movable plate was moved at an angle and rate proportioned that corresponded to the movement of the transducer on the fixed guide. This recorded the echo amplitude B-mode display from a cathode ray tube and provided a record of the cross section of the testes. The movement of these units was synchronized by a sliding coaxial cable connection.

Each testis was individually scanned sequentially from dorsal to ventral poles with the sound beam from the transducer directed to the middle of each testis. Throughout the scanning procedure a continuous flow of paraffin oil from a pressure can was supplied to the face of the transducer so that all air between it and the surface of the polyethylene container was eliminated. The immersion of the testis in warm water served to measure the gently immobilized testis under standard conditions. Also, bulls were generally administered tranquilizers before immersing the testes. By this procedure, profiles of the testis in longitudinal section were recorded on film for 50 bulls. Twenty-six bulls were slaughtered and their ultrasonic profile compared with histopathological examinations of the testes.

\section{Results}

Measurements of testis size, based upon ultrasonography, were similar to those taken with simple calipers [7]. Because the caliper method was simpler, more rapid and accurate, only internal testicular characteristics were evaluated by ultrasonography subsequently.

Ultrasonic frequency measurements made with the 1.6 and $2.25 \mathrm{MHz}$ transducers in Experiment I were compared with other traits (Table 1 ). The mean value and ranges for the frequencies transformed to velocities were $1531 \mathrm{~m} / \mathrm{sec}$ (range $1518-1556 \mathrm{~m} / \mathrm{sec}$ ) for the $2.25 \mathrm{MHz}$ transmitter and $1525 \mathrm{~m} / \mathrm{sec}$ (range 1508-1547 m/sec) for the 1.6 
Table 1. Correlations of testicular ultrasonic measurements with other characteristics of 10 bulls 34 to 42 months old

\begin{tabular}{lcc}
\hline & \multicolumn{2}{l}{ Transmitting transducer used } \\
\cline { 2 - 3 } Variables & $1.6 \mathrm{MHz}$ & $2.25 \mathrm{MHz}$ \\
\hline Ultrasonic frequency correlated with: & & \\
Age of bull & -.29 & $-.64^{*}$ \\
Testis circumference & -.05 & .41 \\
Testis consistency & -.09 & .01 \\
Semen volume & -.13 & -.23 \\
Sperm concentration, 106 & .50 & .24 \\
Sperm per ejaculate, 106 & .29 & .00 \\
Motility of sperm, \% & .01 & .42 \\
Unstained sperm, \% & .05 & .29 \\
Normal sperm, \% & .12 & .52 \\
Sperm motility after freezing & & .19 \\
$\quad$ Semen thawed at 5 C & .31 & .22 \\
$\quad$ Semen thawed at 37 C & .29 & \\
Sperm motility after storage at 5 C & & .34 \\
Stored for 1 day & -.17 & .28 \\
Stored for 2 days & .03 &
\end{tabular}

* $\mathrm{P}<0.05$

Table 2. Correlations of testicular ultrasonic measurements with other characteristics of 68 bulls

\begin{tabular}{lcc}
\hline \multirow{2}{*}{ Variables } & \multicolumn{2}{c}{ Transmitting transducer used } \\
\cline { 2 - 3 } & $1.6 \mathrm{MHz}$ & $2.25 \mathrm{MHz}$ \\
\hline Ultrasound correlated with: & & \\
Age $^{\mathrm{a}}$ & $-.53^{* *}$ & $-.37^{*}$ \\
Testis circumference $_{\text {Testis consistency }}$ & -.29 & $-.51^{* *}$ \\
\hline
\end{tabular}

aThirty-three bulls examined with the $1.6 \mathrm{MHz}$ transmitter ranged in age from 24 to $144 \mathrm{mo}$. and 35 bulls in the other group ranged in age from 20 to 144 months. ${ }^{*} \mathrm{P}=<0.05,{ }^{* *} \mathrm{P}=<0.01$

$\mathrm{MHz}$ transmitter. These values are typical for soft tissue and there was no difference among bulls (P>0.05). Thus, there was little difference found among the testes of 10 normal young bulls of similar age by this procedure, and the ultrasonic frequency was not appreciably correlated to various tests of semen quality (Table 1).

In Experiment II, testicular measurements were made on 68 bulls varying greatly in age. There was a difference among bulls that was associated with age (Table 2).

Figure 1 shows a mid-sagittal section through a testis, along with a cross section picture of this testis obtained with the ultrasonic tester and Polaroid camera. From the periphery to the center of the testis in the conventional photograph can be

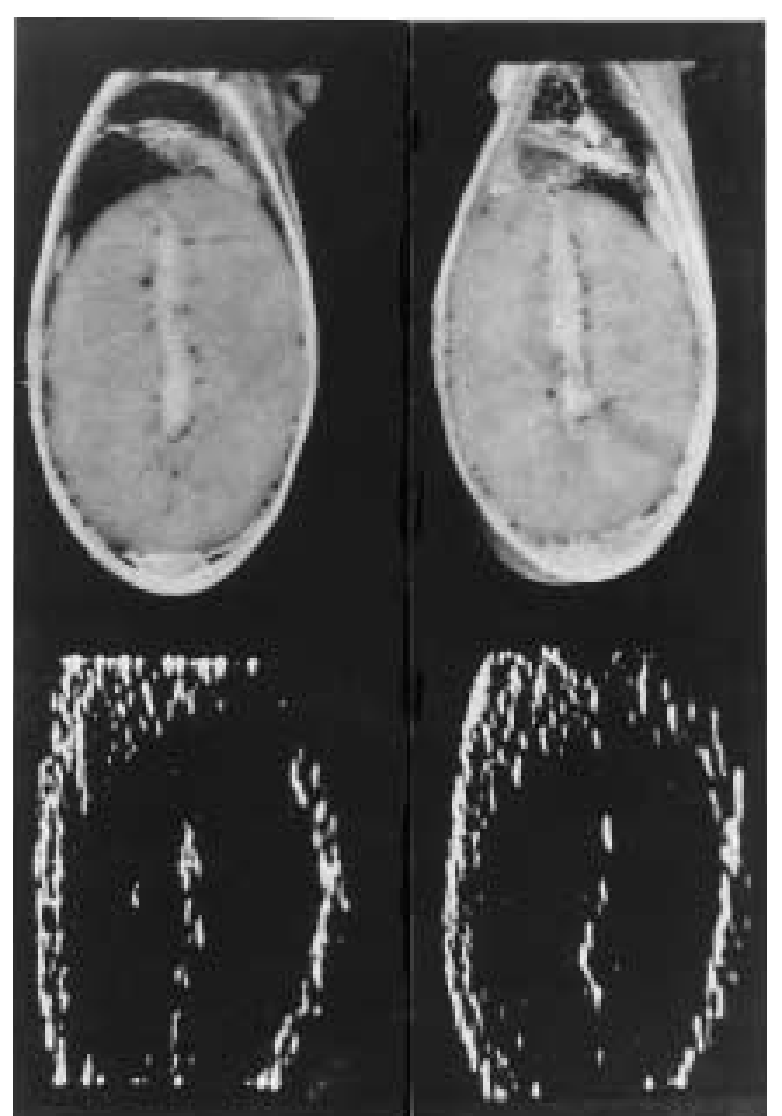

Fig. 1. Testis cut mid-sagittally (above) compared with the ultrasonic scan below. Note the white spots in the ultrasonic scan representing firm connective tissue in contrast to the seminiferous tubular area.

seen the scrotum, tunica vaginalis communis, tunica albuginea with vessels, testis tissue and the mediastinum. Dorsal to the testis, portions of the head of the epididymis, ductus deferens and pampiniform plexus are visible. Ventral to the testis is the tail of the epididymis. The ultrasonogram for this testis viewed in the same direction shows the dense tissue in the area of the scrotum and tunica vaginalis communis, the tunica albuginea outlining the testis, and the mediastinum. Portions of the head of the epididymis and spermatic cord appear dorsal to the testis. In contrast to the reflection of ultrasonic waves by the layers of dense tissue, the homogeneous soft tissue of the seminiferous tubules appears as a dark background. This testis was from a young bull with good semen quality, and was considered to be normal.

The ultrasonograms of many bulls in Experiment III were similar and most appeared to be normal. 


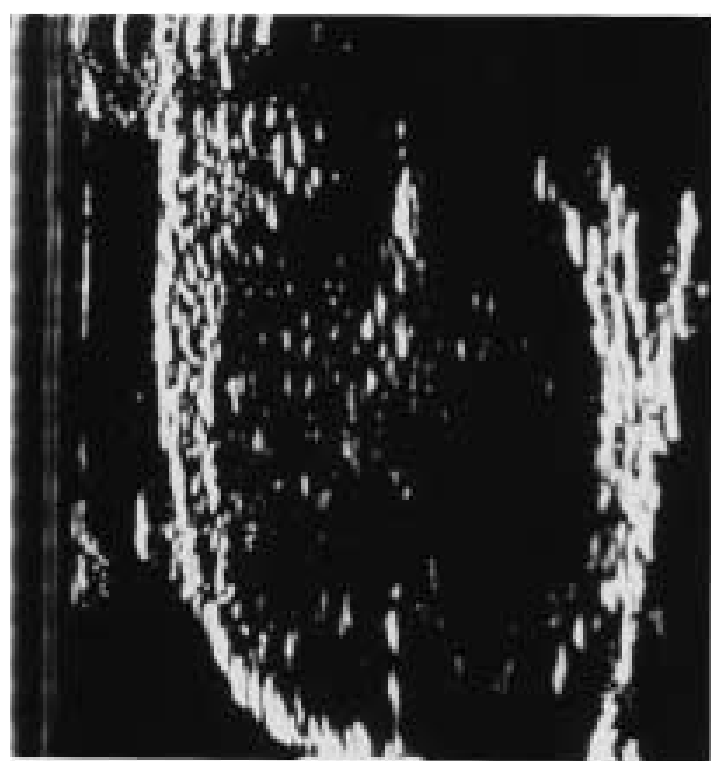

Fig. 2. Ultrasonogram of a testis from a nine-year old bull with reduced semen quality and some infiltration with fibrotic tissue.

Twenty-six bulls were culled and slaughtered. Upon necropsy 13 were classified as having a substantial connective tissue component with fibrosis, as described by McEntee [8], and 13 were judged to be normal. Classification, based upon the ultrasonograms, coincided with 11 of the 13 abnormals and 10 of the 13 normal bulls. Thus, assuming that the postmortem classification was correct, diagnosis by ultrasound was $81 \%$ accurate. Several of the bulls had previous histories of semen collection and those with poor semen quality were in the group judged to have testes with substantial fibrotic tissue.

\section{Discussion}

The importance of breeding bulls having large testes, with a high correlation between testis size, testis weight and sperm output, has been wellestablished $[3,4,7]$. Testis size can be calculated accurately from linear measurements made with calipers or from scrotal circumference [7]. These measurements have a high repeatability. The firmness of testes can be measured objectively with a tonometer [9], and these measurements are highly correlated with semen quality and fertility.

The questions raised in our earlier studies (Hahn, Stouffer and Foote, unpublished, Cornell

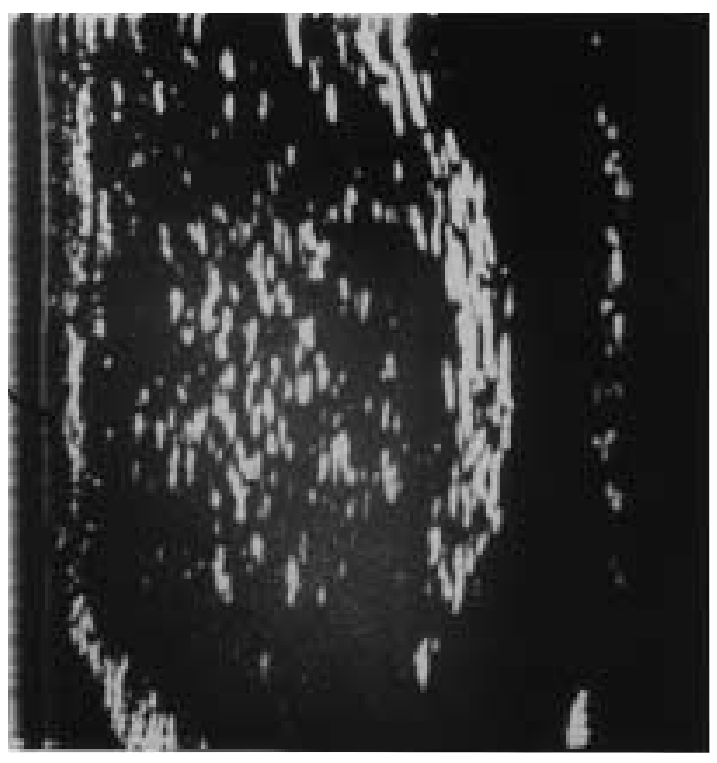

Fig. 3. Ultrasonogram of a testis from a 12-year old bull with poor semen quality and extensive fibrosis noted at necropsy.

University, 1969) was can ultrasound be used to improve morphologic measurements related to testis function and will radiation from ultrasound cause any testicular damage? The initial studies revealed that exposure of rabbit testes to a much higher dose of ultrasonic radiation than was required for making a clinical diagnosis had no effect upon the testes [10]. This finding is consistent with the study by Coulter and Bailey [13], working with beef bulls. Ultrasonography was not a practical way to measure testis size, as testis size was measured more easily, simply and inexpensively with calipers or a scrotal tape than by ultrasonography. This finding is consistent with other studies [14, 15].

Attention then was focused on evaluating internal structures in the testis. Ten normal young bulls were examined with low frequency ultrasound radiation. There was no significant differences among bulls in ultrasound measurements and there was no relationship to semen quality (Table 1). Cartree et al. found no difference among bulls judged to be normal based upon a breeding soundness examination [14]. Likewise, in a more extensive study of beef bulls 13 to 31 or more months old, Eilts and Pechman [16] found no remarkable differences obtained by ultrasonography that were not evident from a concurrent breeding soundness examination. 
In Experiment II, there tended to be a difference in the ultrasonic pattern as bulls aged, and it was observed grossly that old bulls at slaughter tended to have more fibrotic tissue in their testes. This was consistent with the reports $[3,7]$ that sperm output per gram of testis was lower in old bulls.

In Experiment III there were 26 bulls slaughtered that had their testes evaluated ultrasonically before slaughter. Thirteen bulls were judged to have normal testes at necropsy and 13 had extensive fibrotic tissue, as described earlier by McEntee [8]. The concurrence between the classification at necropsy and prediction of normal or abnormal testes derived from the ultrasonic pattern was $81 \%$. In a few cases sperm output obtained by frequent semen collection was known, and problem bulls tended to have more parenchymal tissue replaced with connective tissue. Thus, ultrasound was of value in examining the testes of aged bulls in AI with low sperm output and poor semen quality. These bulls all had the outward appearance of normal testes.
Griffin and Ginther [1] and Ribadu and Nakao [2] reviewed many applications of ultrasonography. An example of using currently available high resolution equipment to advantage to study the development of bull testes and accessory sex glands from 2 to $46 \mathrm{wk}$ of age has been reported [17]. The pathology reported here can be detected using commercially available high frequency tranducers, as recently reported by Sawamukai [18]. Although the clinical use of ultrasound has limited advantages in characterizing the reproductive fitness of bulls and other males, it can be valuable under selected circumstances, as described in this report.

\section{Acknowledgments}

The authors are grateful to Genex Cooperative, Inc., Ithaca, New York for making the bulls available.

\section{References}

1. Griffin PG, Ginther OJ. Research applications of ultrasonic imaging in reproductive biology. J Anim Sci 1992; 70: 953-972.

2. Ribadu AY, Nakao T. Bovine reproductive ultrasonography: A review. J Reprod Dev 1999; 45: 13-28.

3. Willet EL, Ohms JL. Measurement of testicular size and its relationship to production of spermatozoa by bulls. J Dairy Sci 1957; 40: 15591569.

4. Foote RH. Research techniques to study reproductive physiology in the male. In: Becker DE (ed.), Techniques and Procedures in Animal Production Research. Albany, N.Y: ASAP; 1969: 81-110.

5. Foote RH. Artificial Insemination to Cloning. Tracing 50 Years of Research. 1998; 231 pp. Published by the author, Cornell University, Ithaca, NY.

6. Paufler SK, Van Vleck LD, Foote RH. Estimation of testicular size in the live rabbit. Int J Fert 1969; 14: 188-191.

7. Hahn J, Foote RH, Seidel GE, Jr. Testicular growth and related sperm output in dairy bulls. J Anim Sci 1969; 29: 41-47.

8. McEntee K. Pathological conditions in old bulls with impaired fertility. J Amer Vet Med Assoc 1958;
132: 328-331.

9. Hahn J, Foote RH, Cranch ET. Tonometer for measuring testicular consistency of bulls to predict semen quality. J Anim Sci 1969; 29: 483-489.

10. Hahn J, Foote RH. Ultrasonic treatment of rabbit testes. J Anim Sci 1969; 28: 230-232.

11. Stouffer JR. Objective technical methods for determining carcass value in live animals with special emphasis on ultrasonics. World Review of Anim Prod 1966; 1: 59-66.

12. Stouffer JR. Techniques for the estimation of the composition of meat animals. In: Becker DE (ed.), Techniques and Procedures in Animal Production Research. Albany, New York: ASAP; 1969; 207219.

13. Coulter GH, Bailey DRC. Effects of ultrasonography on the bovine testis and semen quality. Theriogenology 1988; 30: 743-749.

14. Cartree RE, Gray BW, Powe TA, Hudson RS, Whiteside J. Preliminary implications of B-mode ultrasonography of the testicles of beef bulls with normal breeding soundness examination. Theriogenology 1988; 31: 1149-1157.

15. Bailey T, Hudson RS, Powe TA, Riddel MG, Wolfe DF, Carson RL. Caliper and ultrasonographic measurements of bovine testicles and a mathematical formula for determining testicular 
volume and weight in vivo. Theriogenology 1998; 49: 581-594.

16. Eilts BE, Pechman RD. B-mode ultrasound observation of bull testes during breeding soundness examinations. Theriogenology 1988; 30: 1169-1175.

17. Chandolia RK, Honaramooz A, Omeka BC, Pierson R, Beard AD, Rawlings NC. Assessment of development of the testes and accessory glands by ultrasonography in bull calves and associated endocrine changes. Theriogenology 1997; 48: 119_ 132.

18. Sawamukai Y. The techniques and applications of ultrasonography for detection of pathological reproductive organs in cattle and horses. J Reprod Dev 1998; 44: j53-j60. 